DOI: http://dx.doi.org/10.15359/rgac.1-56.11

Revista Geográfica de América Central. № 56 ISSN 1011-484X, enero-junio 2016

pp. 259-288

\title{
LOS NIVELES DE VULNERABILIDAD SOCIAL DE LA CIUDAD DE CHILPANCINGO, GUERRERO, MÉXICO
}

\author{
THE LEVELS OF SOCIAL VULNERABILITY OF THE \\ CITY OF CHILPANCINGO, GUERRERO, MEXICO
}

\author{
Neftalí García Castro ${ }^{1}$ \\ Salvador Villerías Salinas ${ }^{2}$ \\ Universidad Autónoma de Guerrero, México
}

\section{RESUMEN}

Esta investigación revela los niveles de vulnerabilidad social hallados en la ciudad de Chilpancingo, Guerrero. Se abordan los aspectos siguientes: primero, el sustento cognoscitivo en torno a la vulnerabilidad social; en particular, aquellos aportes hechos en América Latina que definen el enfoque conceptual utilizado en el presente estudio. Después, se detalla la secuencia empleada para determinar las diferencias socioterritoriales que presenta este asentamiento guerrerense; con base en el método de tipificación probabilística, el cual dio pauta para evaluar el acceso heterogéneo a un conjunto de activos y estructura de oportunidades que inciden en los niveles de vulnerabilidad social de la población examinada. Finalmente, se explica cuál es el comportamiento de los

1 Doctor en Geografía por la Universidad Nacional Autónoma de México. Joven investigador del Programa de Cátedras CONACYT, comisionado como Profesor-investigador en la Maestría en Ciencias: Territorio y Sustentabilidad Social, programa adscrito al Centro de Investigación y Posgrado en Estudios Socioterritoriales de la Universidad Autónoma de Guerrero. 16 de septiembre núm. 42, Barrio de San Mateo, Chilpancingo, Guerrero. c.p.39000. Correo electrónico: ngarciaca@conacyt.mx

2 Doctor en Geografía por la Universidad Nacional Autónoma de México. Profesor-investigador de la Maestría en Ciencias: Territorio y Sustentabilidad Social, programa adscrito al Centro de Investigación y Posgrado en Estudios Socioterritoriales de la Universidad Autónoma de Guerrero. 16 de septiembre núm. 42, Barrio de San Mateo, Chilpancingo, Guerrero. c.p.39000. Correo electrónico: svilleriass@gmail.com 
Neftali Garcia Castro, Salvador Villerias Salinas. The levels of social vulnerability

of the City of Chilpancingo, Guerrero, Mexico

DOI: http://dx.doi.org/10.15359/rgac.1-56.11

indicadores socioeconómicos que distingue a cada nivel de vulnerabilidad social identificado en esta localidad mexicana.

Palabras clave: vulnerabilidad social, tipificación probabilística, Chilpancingo, Guerrero, México.

\section{ABSTRACT}

This paper reveals the social vulnerability levels of the city of Chilpancingo, Guerrero. First, we present the cognitive support around social vulnerability; in particular, those conceptual approach used in this research. Then, we describe the sequence used to determine the socio-territorial differences of this Mexican city -based on the probabilistic classification method, which established the guidelines to assess the heterogeneous access to a set of assets and opportunity structure to determine the levels of social vulnerability of the population analyzed. Finally, we explain the behavior of socio-economic indicators that characterizes each level of social vulnerability identified in Chilpancingo.

Keywords: Social vulnerability, probabilistic classification, Chilpancingo, Guerrero, Mexico.

\section{Introducción}

En México, los fenómenos hidrometeorológicos, procesos de remoción en masa y sismos han sido tratados en numerosas ocasiones, destacan las investigaciones hechas en instituciones como la Universidad Nacional Autónoma de México, algunas universidades públicas estatales, El Colegio de México y el Centro de Investigaciones y Estudios Superiores en Antropología Social. Se han estudiado los aspectos siguientes: 1) las particularidades del evento en cuestión (causa, evolución, impacto), 2) la organización social y comunitaria para salvaguardar la integridad de la población afectada y poner en marcha medidas que reduzcan los daños, y 3 ) los atributos socioeconómicos que explican porque ciertos grupos suelen ser más afectados que otros (Rodríguez, 2004).

No obstante, la literatura en torno al estado de Guerrero, o parte de este, es escasa; la mayoría de las aportaciones exploran, principalmente, las características de los fenómenos naturales que han ocurrido en la entidad, muestra de esto son los textos de López (2009), Arreola (2011) y Villafuerte (2014). No existen trabajos que examinen los factores antropogénicos que restringen la capacidad de los guerrerenses para hacer frente a las situaciones adversas originadas por los fenómenos que amenazan tanto su integridad física como el desarrollo de sus actividades cotidianas ${ }^{3}$.

3 Ese tema cobró notabilidad debido a que, en septiembre de 2013, la interacción del huracán Ingrid, formado en el Golfo de México, y la tormenta tropical Manuel, en el Pacífico, ocasionó lluvias en $80 \%$ de la superficie nacional. Guerrero fue uno de los espacios que reportó más efectos adversos asociados con los escurrimientos pluviales, como consecuencia del desbordamiento de corrientes y cuerpos de agua, así 
Todo análisis de los espacios expuestos a fenómenos potencialmente destructivos debe ponderar minuciosamente sus niveles de vulnerabilidad social; estos denotan el tipo de estratificación, organización e interacción social que favorece o limita el acceso a activos y estructura de oportunidades, lo que da pauta para comprender por qué la población suele ser afectada de manera y magnitud distinta (Cutter, Boruff y Shirley, 2003; Birkmann y Fernando, 2008). Por ejemplo, en la investigación "Características del impacto socioeconómico de los principales desastres ocurridos en México en el período 1980-99" se señala que el mayor número de defunciones y damnificados se concentra en los grupos socioeconómicamente desfavorecidos, estos además constituyen porcentajes significativos de la población que habita en las entidades que registran, de manera frecuente, fenómenos sísmicos o hidrometeorológicos, tal es el caso de Guerrero (Bitrán, 2001).

Chilpancingo, la capital de esa entidad, es un polo de atracción migratoria regional debido a su relevancia político-administrativa y comercial. De acuerdo con el Instituto Nacional de Estadística y Geografía (INEGI), es el segundo centro urbano más habitado del estado, alberga 187251 personas (5.5\% del total estatal) (INEGI, 2015). Si bien esta localidad es concebida por muchos guerrerenses como el sitio que les puede brindar oportunidades laborales, también es escenario de dificultades socioterritoriales diversas como contaminación, reducción de áreas verdes, desabasto de agua, déficit de vivienda, proliferación de asentamientos irregulares y la presencia de segmentos de población con niveles importantes de vulnerabilidad social.

En ese sentido, la exploración de las disparidades socioeconómicas que existen al interior de un espacio puede adquirir un matiz básicamente descriptivo, a menos que sean estudiadas bajo una concepción tipológica como la propuesta por la tipificación probabilística que permite separar y clasificar a las áreas en tipos geográficos con atributos espaciales concretos (Propin y Sánchez, 1998). Esto resulta útil para el ordenamiento territorial, ya que éste busca la definición de un modelo territorial deseable,

como derivados de los movimientos gravitacionales que tuvieron lugar en la entidad; lo que ocasionó más de un centenar de defunciones, 238000 personas damnificadas, alrededor de 13000 viviendas con algún tipo de deterioro, daños significativos en la infraestructura carretera, interrupción de la comunicación vía área y la pérdida de aproximadamente 150000 hectáreas de cultivos. En la ciudad de Chilpancingo, la tormenta tropical mencionada desbordó la presa Cerrito Rico y el río Huacapa, lo que produjo inundaciones en decenas de sitios, sobre todo en aquellos ubicados cerca a esa corriente superficial (Secretaría de Gobernación, 2015). 
Neftali Garcia Castro, Salvador Villerias Salinas. The levels of social vulnerability

of the City of Chilpancingo, Guerrero, Mexico

DOI: http://dx.doi.org/10.15359/rgac.1-56.11

mediante un proceso ejecutivo que se ocupe de la localización y distribución espacial de aquellos factores que influyen en el desarrollo y bienestar de la población (Cabrales, 2006).

Esta investigación tiene como finalidad revelar las áreas prioritarias para la gestión de los riesgos asociados con los fenómenos de origen natural o antrópico que suelen presentarse en la ciudad de Chilpancingo. El documento se suma a los trabajos que consideran indispensable la evaluación de la vulnerabilidad social como un aspecto fundamental que debe tomarse en cuenta para formular criterios de prevención, valorar el impacto potencial y las acciones posteriores a la ocurrencia de eventos que genera consecuencias adversas ${ }^{4}$.

\section{Sustento cognoscitivo}

El concepto de vulnerabilidad ha recibido aportes de campos de conocimiento distintos (antropología, sociología, psicología, ecología, geografía, ingeniería); en consecuencia, la literatura para estructurar un marco conceptual es vasta y heterogénea. Dicha expresión suele acotarse a partir de una serie extensa de elementos como el riesgo, las estrategias para enfrentar a este, susceptibilidad, adaptación, resiliencia, sensibilidad, estrés, entre otros (Ruíz, 2011; Sánchez y Egea, 2011; Cecchini et al., 2012). Por lo tanto, con el propósito de facilitar la comprensión del presente trabajo, a continuación se exponen las concepciones reveladas por algunos estudios desarrollados en América Latina, las cuales delimitan el enfoque cognoscitivo empleado para escudriñar los niveles de vulnerabilidad social de la ciudad de Chilpancingo.

La vulnerabilidad social se ha robustecido como alternativa teóricoconceptual para explicar el conjunto de transformaciones derivadas de los ajustes estructurales y aspectos distintos de la globalización causantes de la incertidumbre socioeconómica que aqueja a sectores amplios de la población, sobre todo aquellos con ingresos medios y bajos (Busso, 2005; Moreno, 2008). Esto tiene un matiz trascendental debido a que las desigualdades sociales se han agudizado, las políticas orientadas a su reducción han sido poco efectivas y además son afectadas por los habituales

4 Este trabajo forma parte del proyecto Gestión multidisciplinaria del riesgo ante fenómenos sísmicos e hidrometeorológicos en Guerrero y recibe financiamiento del Consejo Nacional de Ciencia y Tecnología. 
recortes al gasto social que caracterizan al modelo neoliberal (Kaztman, 2000; Beck, 2008; Cecchini, op. cit.) $)^{5}$.

La vulnerabilidad suele ser considerada "una condición de indefensión, la susceptibilidad a sufrir algún tipo de daño o perjuicio, o de padecer incertidumbre" (Moreno, op. cit., p.2). Es la probabilidad de que una persona, hogar o grupo padezca tal reducción en su bienestar que le coloque por debajo del nivel mínimo de este (Cecchini et al., op. cit.). De acuerdo con el Centro Latinoamericano de Demografía (CELADE), la vulnerabilidad es producto de los factores siguientes: 1) la probabilidad de que ocurra un evento con efectos adversos, 2) la mínima o nula respuesta frente a tal contingencia, debido a la falta de mecanismos de defensa apropiados (tanto de carácter endógeno como derivados de fuentes de apoyo externo) y 3) la inhabilidad para adaptarse al nuevo escenario derivado de la materialización del riesgo (CELADE, 2002) ${ }^{6}$.

En consecuencia, la vulnerabilidad social denota el estado de una persona, hogar o un grupo, el cual "varía en relación inversa a su capacidad para controlar las fuerzas que modelan su propio destino, o para contrarrestar sus efectos sobre el bienestar" (Kaztman, op. cit., p.8). Es "la incapacidad de una persona o de un hogar para aprovechar las oportunidades, disponibles en distintos ámbitos socioeconómicos, para mejorar su situación de bienestar o impedir su deterioro" (Ibid., p.13). De esta manera, tal estado de incapacidad es concebido como resultado de la combinación de eventos, procesos y aquellas características, individuales o colectivas, que pueden dificultar la subsistencia, el acceso a mayores niveles de bienestar, el ejercicio de los derechos humanos, así como la consolidación de proyectos a nivel personal, familiar o comunal (Golovanevsky, 2007; Adamo, 2012).

5 Al respecto, Pizarro (2001) sugiere que desde "la constitución de los estados independientes, la pobreza y la mala distribución del ingreso estuvieron presentes en el capitalismo subdesarrollado latinoamericano. A éstos fenómenos se agrega la vulnerabilidad social como rasgo específico de la forma que ha adoptado el capitalismo en los últimos años: economía de libre mercado, abierta al mundo y con "estado mínimo". Así como en el pasado la denominada "industrialización por sustitución de importaciones" (ISI) tuvo en la marginalidad su fenómeno social más distintivo, en el actual período histórico la vulnerabilidad aparece como el rasgo dominante del patrón de desarrollo vigente" (p.5).

6 El riesgo aquí es definido como "la posibilidad de que una contingencia (ocurrencia o presencia de un evento, característica o proceso) entrañe efectos adversos para [...] la comunidad, hogar, persona, empresa, ecosistema, etc. [...] El riesgo no alude a un acontecimiento intrínsecamente negativo, sino a uno que puede generar daño o incertidumbre y cuyas consecuencias pueden ser ambiguas o mixtas, combinando adversidad y oportunidad.” (CEPAL-ECLAC, 2002, p.3 citado por Caro, 2003). 
Neftali Garcia Castro, Salvador Villerias Salinas. The levels of social vulnerability

of the City of Chilpancingo, Guerrero, Mexico

DOI: http://dx.doi.org/10.15359/rgac.1-56.11

Todo esto es originado por causas múltiples derivadas de procesos económicos, políticos y culturales del modelo económico vigente; sin embargo, sobresalen las siguientes: el deterioro del mercado laboral, la volatilidad de los ingresos económicos, la distribución desigual de los activos y la condición endeble adquirida por instituciones sociales como el Estado (Busso, op. cit.; CELADE, op. cit.; Caro, 2003) ${ }^{7}$. De igual forma, son relevantes ciertas conductas que suponen mayor exposición a eventos dañinos, así como atributos básicos de la población como la edad, género, nivel educativo, condición étnica, composición del hogar, nivel socioeconómico, estatus ocupacional, entre otros que se considera suelen realzar los riesgos o las dificultades (Ibid.).

Otro aspecto medular de la vulnerabilidad social es su carácter coyuntural, ya que si bien existe una propensión estructural básica, esta suele adquirir niveles distintos cuando surge un evento que impacta de manera desfavorable; "de acuerdo con el transcurso de la crisis y con el encadenamiento de los procesos que le acompañan y sus consecuencias perdurables, y de acuerdo con la capacidad de resistencia y de superación de los afectados" (Coy, 2010, p.21). Por lo tanto, la vulnerabilidad social tiene variaciones espacio-temporales ocasionadas por la heterogeneidad de los eventos y demás causas que inciden en su manifestación; por ejemplo, la distribución disímil de la población, las características de ésta y su evolución a lo largo del tiempo, la presencia diferenciada de infraestructura de servicios, oportunidades laborales, etc. (Adamo, op. cit.).

El carácter polisémico de la vulnerabilidad social ha originado propuestas metodológicas múltiples (Busso, 2002). Varias sugieren la construcción de indicadores con base en información obtenida en censos o encuestas, ya que estos instrumentos cuantitativos dan pauta para elaborar caracterizaciones territoriales, tal es el caso de los trabajos de Busso (op. cit.), Alfageme y Carrasco (2010), Lampis (2010) y Vergara (2011). Desafortunadamente, en la mayoría de los países en desarrollo, las fuentes oficiales de información estadística no poseen las variables suficientes

7 En ese sentido, en decenios recientes, en América Latina "la apertura al mundo, el predominio del mercado en la vida económica y el repliegue del estado de las funciones que tuvo en el pasado ampliaron los espacios de actuación de ciertas capas de la población, con nuevas y mayores oportunidades profesionales y de negocios. Pero, por otra parte, también provocaron un cambio tan rápido y de tanta envergadura en la economía y en las instituciones que acentuaron las condiciones de vulnerabilidad de las personas y familias de ingresos medios y bajos" (Pizarro, op. cit., p.10). 
para elaborar un análisis integral de la vulnerabilidad social (Kaztman, op. cit.). Por otra parte, las investigaciones producto de la recopilación de datos en campo tienen una cobertura territorial reducida, debido a los recursos financieros y humanos que suele demandar la puesta en práctica de esa técnica.

No obstante, un número substancial de estudiosos considera esencial evaluar los aspectos siguientes: 1) los recursos materiales y simbólicos que favorecen o dificultan el desempeño de las personas en su contexto social (capital financiero, capital humano, experiencia laboral, nivel educativo, composición y atributos de la familia, capital social, participación en redes y capital físico, entre otros); 2) la estructura de oportunidades (determinadas por el mercado, el Estado y la sociedad), las cuales varían debido a las crisis o el crecimiento económico, las transformaciones de la estructura productiva, los cambios tecnológicos y las diversas políticas públicas; y 3 ) instituciones y relaciones sociales que las personas desarrollan como acción colectiva (familia, sindicatos, empresas, movimientos sociales, partidos políticos) (Pizarro, op. cit.; Busso, op. cit.; Filgueira, 2005 citado por Golovanevsky, op. cit.).

Desde esa óptica, el impacto diferenciado de un evento dañino refleja rasgos esenciales de interacción, organización y, en particular, del modelo de estratificación social que regula el acceso a recursos como los señalados en el párrafo precedente, los cuales inciden sobre la capacidad de anticipar, lidiar, resistir o recuperarse de situaciones críticas (Coy, op. cit.; Ruiz y Grimalt, 2012) ${ }^{8}$. Esto ha sido confirmado en investigaciones que sustentan que la vulnerabilidad social es mayor cuando los activos y la estructura de oportunidades son insuficientes (Filgueira, op. cit.). En consecuencia, su análisis suele relacionarse con el estudio de la pobreza, falta de instrucción formal y desprotección social (Derrick et al, 1968 citado por Aneas, s/f).

Tales vínculos son explorados, ampliamente, en los trabajos de Busso (op. cit.), Filgueira (op. cit.), Lampis (op. cit.), Sales (2012), Águila

8 Ruiz y Grimalt (op. cit.), en su investigación sobre vulnerabilidad social frente a desastres naturales, expresan que "las sociedades desarrolladas y estructuradas tienen mayor capacidad de responder a los desastres, son más resilientes tanto en la fase de emergencia como en la fase de recuperación. Las causas son variadas: por la calidad de sus construcciones e infraestructuras, por su información sobre la catástrofe y de cómo responder frente a la misma, por sus sistemas de alerta temprana, por su capacidad de reacción y movilización, por su estructura organizativa, por los sistemas de gestión de la emergencia, y sobre todo, por su capacidad económica que las permite recuperarse.” (p. 1). 
Neftali Garcia Castro, Salvador Villerias Salinas. The levels of social vulnerability

of the City of Chilpancingo, Guerrero, Mexico

DOI: http://dx.doi.org/10.15359/rgac.1-56.11

et al. (2013) y Quinn (2013). Estos autores identifican las principales características estructurales que limitan el desarrollo individual y colectivo de las personas y, por ende, acentúan la vulnerabilidad social de sectores distintos de población. Esencialmente, se trata de aquellos atributos socioeconómicos ocasionados por la acumulación disímil de capacidades y bienes de capital (Sales, op. cit.).

Asimismo, existen trabajos que evalúan, concretamente, la relación que hay entre esos dos últimos aspectos y la capacidad para enfrentar situaciones de emergencia, derivadas de un fenómeno natural o antrópico que pone en riesgo la integridad física y el desarrollo de las actividades cotidianas de las personas; destacan los exámenes elaborados por Bitrán ( $o p$. cit.), Juárez, Iñiguez y Sánchez (2006), Birkmann y Fernando (op. cit.), Salamanca (2009), Ruiz y Grimalt (op. cit.) y Ruiz (2012). La mayoría de esas obras sugiere que el concepto de vulnerabilidad social permite abordar los efectos adversos de ese tipo de fenómenos, desde una perspectiva crítica que subraya las disparidades sociales y económicas de la población, las cuales motivan que ciertos segmentos de esta resulten más afectados que otros. Salamanca (op. cit.) formula que:

Las personas que se encuentran en la línea de pobreza y con insuficientes capacidades, ven agravada su situación cuando se enfrentan a desastres causados por fenómenos naturales o antrópicos, es así que estas personas, aparte de realizar un esfuerzo muy grande para posibilitar su reproducción cotidiana, deben incrementar este esfuerzo para reponer los bienes y medios de vida perdidos. Si a esto se añade que no existe una política de protección social, lo único que les queda es sobrevivir en peores condiciones, pudiendo llegar en algunos casos a la indigencia. (p.5).

\section{Propuesta metodológica}

Esta obra es la primera que utiliza la tipificación probabilística para escudriñar la vulnerabilidad social. Esta vertiente cognoscitiva fue desarrollada por Thürmer en el Departamento de Geografía Económica del Instituto de Geografía y Geoecología de la Academia de Ciencias de la República Democrática Alemana, a principio del decenio de los ochenta. El método requiere que se desarrollen comparaciones tanto cuantitativas como cualitativas que gravitan en torno a aquellos sitios que fungen como los extremos de la gama de condiciones socioeconómicas, propia de todo 
espacio. Esto da pauta para alcanzar una interpretación espacial abstracta y sintética que debe estar vinculada con la confección de material cartográfico, ya que este recurso investigativo permite expresar, en forma sencilla, la compleja organización socioeconómica del territorio abordado9 .

Se optó por esta solución metodológica porque revela agrupamientos de procesos u objetos de interés, a partir de la repetividad, similitud, homogeneidad y jerarquía territorial (Propin, 2003). El enfoque tipológico resume distintos atributos asociados con el hecho, fenómeno o proceso en cuestión; lo que facilita la conformación de grupos o tipos discretos que, en lo fundamental, constituyen instrumentos valiosos para examinar integralmente el comportamiento de las variables o indicadores que se compendian, de acuerdo al marco teórico-conceptual de referencia (Sánchez, 2000).

En ese orden de ideas, en esta investigación se define al nivel de vulnerabilidad social como la expresión medible que resulta del tratamiento metodológico de indicadores socioeconómicos, los cuales se seleccionan con la finalidad de ponderar la magnitud de la indefensión, la susceptibilidad a sufrir daño o la incertidumbre que padecen los habitantes de una espacio concreto. La secuencia que se utilizó fue la siguiente:

a) Selección de unidades espaciales de análisis. Para garantizar un examen con detalle territorial significativo, se utilizó la Área Geoestadística Básica urbana (AGEB). Con esto se supera una de las dificultades asociadas con la factibilidad de aplicación de la tipificación probabilística como alternativa metodológica: la mínima cantidad de unidades político-administrativas presentes en cierto territorio. Cuanto menor sea el número de circunscripciones, menos efectivo es el enfoque tipológico (Propin, op. cit.)10.

b) Selección de indicadores socioeconómicos. La tipificación probabilística requiere que el número total de indicadores utilizados no sea

9 En América Latina, las directrices metodológicas de la tipificación probabilística fueron dadas a conocer por Propin (1989), en un mapa que clasificó al territorio de Cuba de acuerdo con su dinámica poblacional y económica. Desde entonces se han concretado varios trabajos que exponen las desproporciones económicoterritoriales presentes al interior de distintos estados de la República Mexicana (García, 2011).

10 Según el INEGI, una AGEB urbana es un área geográfica ocupada por un conjunto de manzanas delimitadas por calles, avenidas, andadores o cualquier rasgo de fácil identificación en el terreno y cuyo uso del suelo es principalmente habitacional, industrial, de servicios, comercial, etcétera, y solo son asignadas al interior de las zonas urbanas que son aquellas con población mayor o igual a 2500 habitantes y en las cabeceras municipales (CONEVAL, 2015). 
mayor a cinco, ni menor a tres. Estos deben considerarse mediciones complejas que revelan el comportamiento esencial del hecho o fenómeno de interés, lo cual supone poner mayor atención sobre la cualidad-complejidad de los atributos escogidos, por encima de la cantidad de indicadores seleccionados (Ibid.).

Se usó el índice de marginación urbana (IM) porque, según el Consejo Nacional de Población (CONAPO), advierte "el impacto global de las carencias que padece la población como resultado de la falta de acceso a la educación, a los servicios de salud, la residencia en viviendas inadecuadas y la carencia de bienes" (CONAPO, 2010, p.9). Esta medida refleja la vulnerabilidad social de las personas que tienen acceso mínimo a un conjunto de activos y estructura de oportunidades determinantes del bienestar humano, lo cual incide en las condiciones de vida de la población. Los indicadores restantes se seleccionaron con base en el criterio descrito arriba y después de evaluar que variables económicas y demográficas afinan el escenario socioterritorial revelado por el índice de CONAPO. Se optó por valorar los aspectos siguientes:

Concentración territorial de la población (CTP). Denota la proporción de personas asentadas en una AGEB, respecto al total de la ciudad. Se eligió debido a que la lectura conjunta de este indicador con los otros cuatro da pauta para conocer, de manera sencilla, el porcentaje de residentes de Chilpancingo que reportan un nivel de vulnerabilidad social específico.

Tasa de desocupación (TD). Expone la relación existente entre la población desocupada y la población económicamente activa, en cada AGEB. Es útil para vislumbrar las dificultades del sistema económico para absorber la mano de obra disponible en un espacio concreto. Asimismo, dado que los ingresos laborales son la principal fuente de recursos económicos en los hogares, la tasa de desocupación es fundamental para evaluar el nivel de vulnerabilidad económica de la población (Secretaría de Ambiente y Desarrollo Sustentable, 2015). Relación de dependencia (RD). Es el porcentaje de personas dependientes (menores de 15 años y mayores de 65), respecto a la población ocupada en cada AGEB. Cuanto mayor es el valor que ostenta 
este indicador, en un área determinada, resulta más amplia la proporción de habitantes que debe mantener el segmento demográfico que labora y, por lo tanto, suele aumentar el nivel de vulnerabilidad (Ibid.). Además, esta relación permite distinguir cuanta población infantil y de la tercera edad hay en la unidad de análisis en cuestión, esto es importante porque, con frecuencia, ambos grupos presentan vulnerabilidad significativa.

Porcentaje de hogares con jefatura femenina (HJF). Revela la proporción de hogares encabezados por mujeres, en relación con el total de hogares cuantificados en el espacio evaluado. Investigaciones nacionales e internacionales han expuesto que este tipo de hogares son más vulnerables; por ejemplo, debido a la mayor carga de trabajo a la que se enfrentan las madres solteras y a la falta de conformación de capital común con una pareja (Sales, op. cit.).

c. Conformación de las matrices de datos. Allí se registró toda la información estadística necesaria para calcular los indicadores evaluados y también se muestra la variación cuantitativa de estos en la ciudad de Chilpancingo. Ese compendio de datos es fundamental para determinar los niveles de vulnerabilidad social de este segmento del territorio guerrerense (Cuadro 1).

Cuadro 1. Ejemplo del comportamiento cuantitativo de los indicadores socioeconómicos seleccionados

\begin{tabular}{|c|c|c|c|c|c|}
\hline \multicolumn{1}{|c|}{ AGEB } & CTP & TD & RD & HJF & IM \\
\hline $120290001004 \mathrm{~A}$ & 2.0574 & 4.4668 & 44.4024 & 37.7049 & -0.54829 \\
\hline 1202900010054 & 1.8475 & 2.2142 & 42.2680 & 42.0610 & -0.75593 \\
\hline 1202900010073 & 2.2417 & 4.9618 & 49.8370 & 35.1325 & -0.17034 \\
\hline 1202900010092 & 1.9319 & 5.2243 & 44.5744 & 40.3828 & -0.75174 \\
\hline 1202900010124 & 0.7243 & 3.8400 & 48.9955 & 35.8974 & -0.89574 \\
\hline
\end{tabular}

Fuente: elaborado con base en datos de INEGI, op. cit. y CONAPO, op. cit.

d. Clasificación cualitativa de los indicadores. Esto requiere conformar cinco rangos como vías de generalización cualitativa (Propin, op. cit.). Los calificativos utilizados y su codificación numérica son: muy alta (5), alta (4), media (3), baja (2) y muy baja (1) (Cuadro 2). 
Neftali Garcia Castro, Salvador Villerias Salinas. The levels of social vulnerability of the City of Chilpancingo, Guerrero, Mexico

DOI: http://dx.doi.org/10.15359/rgac.1-56.11

Sucesivamente, se elaboró una nueva matriz, en ella se remplazaron los montos de los cinco indicadores por combinaciones de índices clasificatorios que corresponden a cada AGEB, según el rango asignado a su valor (Cuadro 3).

Cuadro 2. Clasificación cualitativa de indicadores

\begin{tabular}{|l|c|c|c|c|c|}
\hline $\begin{array}{c}\text { Indicador } \\
\text { Rango }\end{array}$ & $\begin{array}{c}\text { CTP } \\
(\%)\end{array}$ & $\begin{array}{c}\text { TD } \\
(\%)\end{array}$ & $\begin{array}{c}\text { RD } \\
(\%)\end{array}$ & $\begin{array}{c}\text { HJF } \\
(\%)\end{array}$ & $\begin{array}{c}\text { IM } \\
(*)\end{array}$ \\
\hline Muy alto (5) & 1.757 a 3.193 & 7.279 a 12.766 & 78.881 a 100.0 & 42.784 a 100.00 & 1.059 a 5.098 \\
\hline Alto (4) & 1.079 a 1.756 & 4.676 a 7.278 & 60.781 a 78.880 & 34.681 a 42.783 & 0.050 a 1.059 \\
\hline Medio (3) & 0.627 a 1.078 & 2.877 a 4.675 & 47.774 a 60.780 & 27.177 a 34.680 & -0.623 a 0.050 \\
\hline Bajo (2) & 0.232 a 0.626 & 0.948 a 2.876 & 5.656 a 47.773 & 11.766 a 27.176 & -0.960 a -0.623 \\
\hline Muy bajo (1) & 0.00 a 0.232 & 0.00 a 0.947 & 0.00 a 5.655 & 0.00 a11.765 & -1.633 a -0.960 \\
\hline
\end{tabular}

Fuente: elaborado con base en datos de INEGI, op. cit. y CONAPO, op. cit.

* Estimaciones del CONAPO con base en el Censo de Población y Vivienda 2010.

Cuadro 3. Ejemplos de indicadores ponderados

\begin{tabular}{|c|c|c|c|c|c|}
\hline AGEB & CTP & TD & RD & PJF & IM \\
\hline $120290001004^{\text {a }}$ & 5 & 3 & 2 & 4 & 3 \\
\hline 1202900010054 & 5 & 2 & 2 & 4 & 2 \\
\hline 1202900010073 & 5 & 4 & 3 & 4 & 3 \\
\hline 1202900010092 & 5 & 4 & 2 & 4 & 2 \\
\hline $\mathbf{1 2 0 2 9 0 0 0 1 0 1 2 4}$ & $\mathbf{3}$ & $\mathbf{3}$ & $\mathbf{3}$ & $\mathbf{4}$ & $\mathbf{2}$ \\
\hline
\end{tabular}

Fuente: elaborado con base en los cuadros 1 y 2 .

e. Conformación de las nubes tipológicas. Se identificaron las combinaciones de índices clasificatorios presentes en la ciudad de Chilpancingo y la frecuencia de cada una de ellas (Cuadro 4). Los códigos más recurrentes fueron considerados núcleos a partir de los cuales se ligaron otros que indican la existencia de AGEBS con características socioeconómicas análogas. Primero, se agruparon aquellos que se desvían, entre sí, en el rango de un solo indicador. Posteriormente, se conectaron los que no cumplieron con la condición anterior. En ese caso, fue esencial ponderar la afinidad que hay entre cierta nube y el código que se anexa. Cabe destacar que los índices que aglutinan valores muy bajos (1) y bajos (2) están vinculados con lugares que 

de la Ciudad de Chilpancingo, Guerrero, México DOI: http://dx.doi.org/10.15359/rgac.1-56.11

poseen mejores condiciones socioeconómicas. Generalmente, estos son los tipos de nubes que aluden a los espacios que presentan menor vulnerabilidad dentro del conjunto que se examina (Figura 1)11.

Cuadro 4. Ejemplo de la frecuencia de códigos identificados

\begin{tabular}{|c|c|c|c|c|c|c|c|c|c|c|c|}
\hline \multicolumn{5}{|c|}{ Código } & Frecuencia & \multicolumn{5}{|c|}{ Código } & Frecuencia \\
\hline 5 & 4 & 3 & 4 & 3 & 1 & 2 & 4 & 4 & 2 & 5 & 1 \\
5 & 4 & 3 & 3 & 4 & 2 & 2 & 4 & 2 & 3 & 3 & 1 \\
5 & 4 & 2 & 4 & 2 & 1 & 2 & 3 & 4 & 3 & 5 & 2 \\
4 & 5 & 3 & 4 & 4 & 1 & 2 & 2 & 3 & 5 & 3 & 1 \\
4 & 4 & 3 & 3 & 4 & 1 & 2 & 2 & 3 & 3 & 5 & 3 \\
4 & 4 & 2 & 4 & 2 & 1 & 2 & 2 & 3 & 2 & 3 & 1 \\
4 & 3 & 3 & 3 & 4 & 5 & 2 & 1 & 4 & 2 & 5 & 2 \\
\hline
\end{tabular}

Fuente: elaborado con base en datos de INEGI, op. cit. y CONAPO, op. cit.

11 También fue necesario establecer los niveles jerárquicos que refieren las nubes tipológicas conformadas. Se ordenaron con base en el comportamiento del coeficiente de correlación de Spearman exhibido entre los indicadores utilizados. Los que ostentaron una reciprocidad alta se tomaron en cuenta para decidir qué lugar ocuparía una determinada nube tipológica; fue el caso de la correlación existente entre la tasa de desocupación y el índice de marginación (0.512), así como entre la concentración territorial de población y la tasa de desocupación (0.406). 
Neftali Garcia Castro, Salvador Villerias Salinas. The levels of social vulnerability of the City of Chilpancingo, Guerrero, Mexico

DOI: http://dx.doi.org/10.15359/rgac.1-56.11

Figura 1. Ciudad de Chilpancingo: agrupación de los códigos en nubes tipológicas
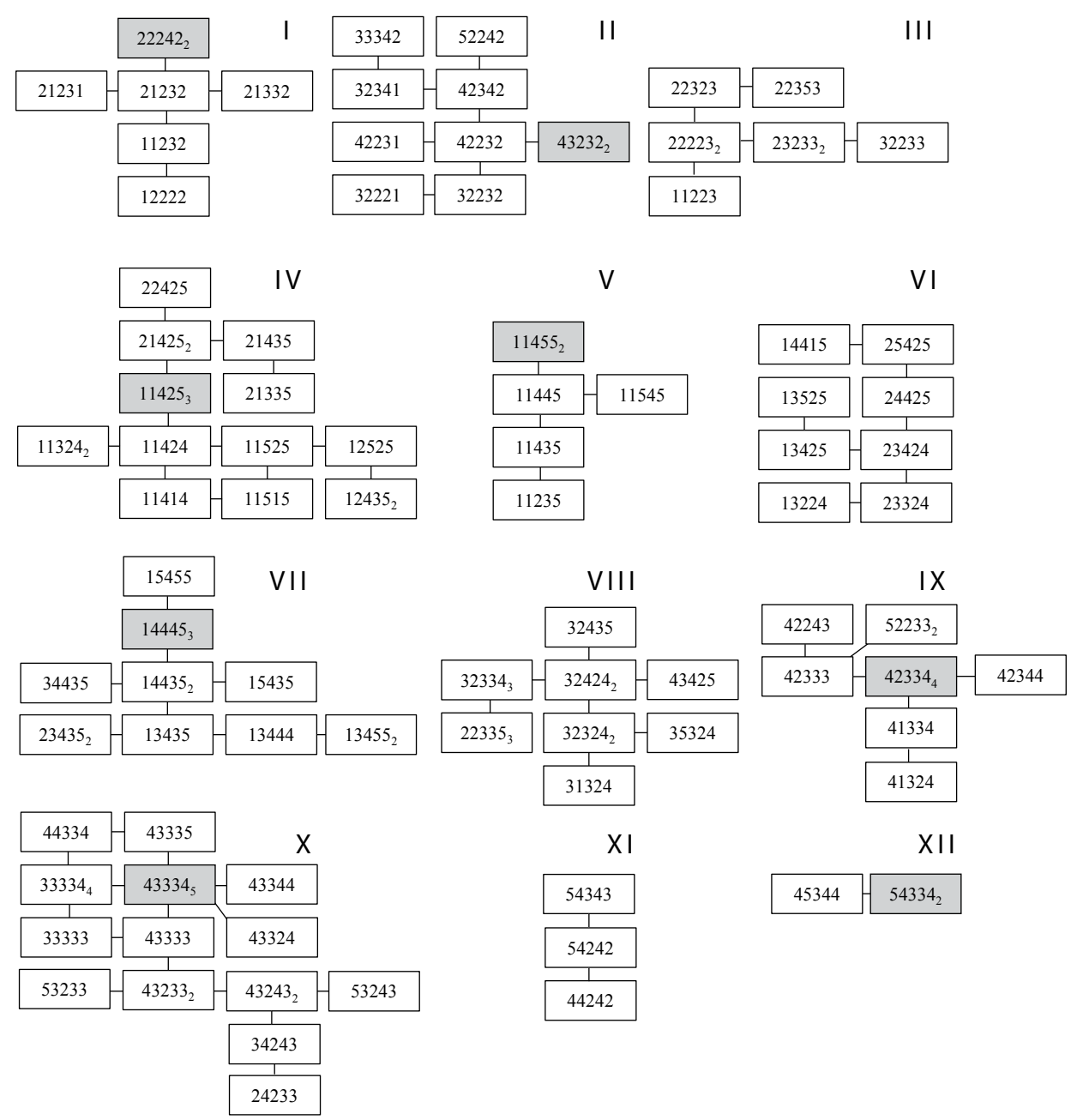

Fuente: elaborado con base en datos de INEGI, op. cit. y CONAPO, op. cit.

f. Revelación de la tipología. Las nubes conformadas se denominan mediante una nomenclatura única que exprese la frecuencia con la que se repite el valor de cada indicador, en el conjunto de índices clasificatorios que agrupa la nube estudiada. Tales variaciones se expresan de las cuatro formas ejemplificadas a continuación (Ibid.). 
1: señala la existencia de valores muy bajos en más de $90 \%$ de los casos de una nube; 23: indica el predominio de un indicador con rango bajo (entre 80 y $90 \%$ del conjunto de casos que conforman a la nube). Los casos secundarios se presentan como subíndices; 2(3): revela el predomino relativo de valores bajos (entre 50 y menos de $80 \%$ de los casos muestra esa condición). Se emplean subíndices y paréntesis para expresar otros rangos que ostenta el indicador en cuestión; y 2,3: significa que los montos bajos y medios aparecen con la misma frecuencia. Esa situación equilibrada se registra mediante el empleo de números de igual dimensión.

\section{Características geográficas de la ciudad de Chilpancingo}

La ciudad de Chilpancingo se localiza en el municipio homónimo del estado de Guerrero; en la región Centro de este, al suroeste de la República Mexicana (Figura 2). Se ubica a 1250 metros de altitud, buena parte del asentamiento original está en el valle del río Huacapa, rodeado por el relieve escarpado de la Cordillera Costera del Sur. Al norte de la localidad destacan las elevaciones conocidas como Tierras Prietas (1 $350 \mathrm{msnm}$ ); al sur, la Sierra de Salto de Valadez; al este, la serranía de Filo de Abismos (2 $100 \mathrm{msnm}$ ); y al oeste, la Cordillera del Culebreado o el Filo Mayor (2 $500 \mathrm{msnm}$ ) (INEGI, op. cit.). En las laderas de algunas de esas formaciones orográficas, la presencia humana es importante debido a la expansión reciente de la mancha urbana, ejemplo de esto son los fraccionamientos y colonias Villas El Parador, Villas Vicente Guerrero, Villas Magisteriales, Río Azul, Rosario Ibarra y Emperador Cuauhtémoc. 
Neftali Garcia Castro, Salvador Villerias Salinas. The levels of social vulnerability of the City of Chilpancingo, Guerrero, Mexico

DOI: http://dx.doi.org/10.15359/rgac.1-56.11

Figura 2. Localización del área de estudio

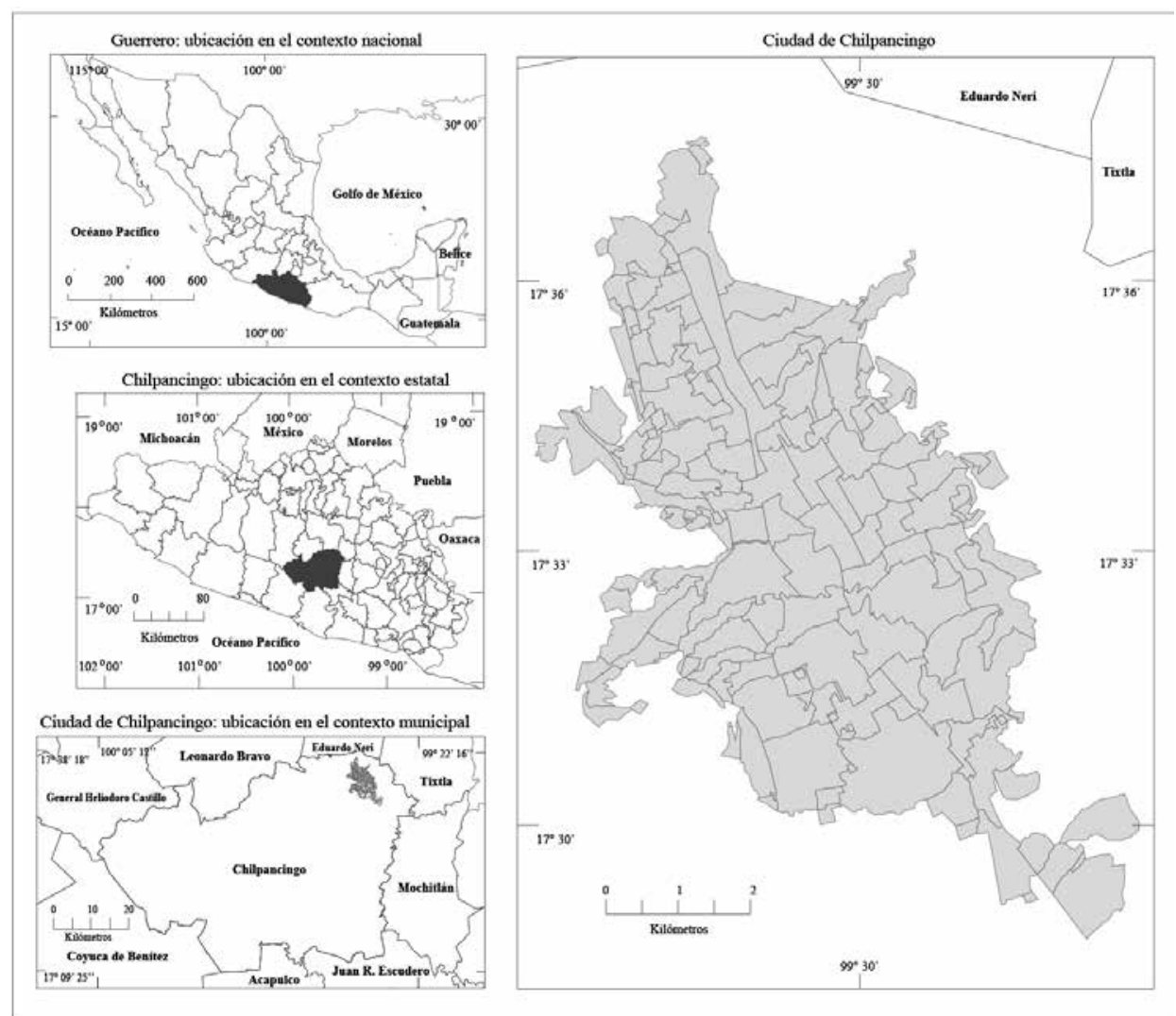

Fuente: elaborado con base en INEGI, op. cit.

El Huacapa es el principal escurrimiento superficial que existe en la capital del estado de Guerrero. Atraviesa la zona urbana de norte a sur, a lo largo de aproximadamente $9 \mathrm{~km}$. Desde hace varios decenios, en ese cauce y en treinta y seis barrancas de la ciudad se vierten las aguas residuales de la misma (CEPEP, 1997). Esto contaminó el río y lo convirtió en foco potencial de infección para la población, en especial para aquella que habita cerca de la zona.

Según la clasificación de Köppen, la ciudad posee clima semicálido subhúmedo con lluvias en verano, el cual se caracteriza por una temperatura media anual mayor a $18^{\circ} \mathrm{C}$, la del mes más cálido supera $22^{\circ}$ y en el mes más frío se registra menos de $18^{\circ}$. Por otra parte, en la época más seca 
del año, la precipitación no rebasa $40 \mathrm{~mm}$. El porcentaje de lluvia invernal tiene un valor comprendido entre 5 y 10.2 del total anual. En verano, la variación del índice de humedad de Lang divide a este asentamiento guerrerense en las áreas siguientes: norte, con menos de 43.2; centro-sur, considerada intermedia en humedad, varía de 43.2 a 55; y el extremo sur presenta más de 55 (INEGI, op. cit.).

El área urbana ocupa superficies extensas que estuvieron cubiertas por leptosol, un suelo delgado que tiene potencial mínimo para el desarrollo actividades agrícolas, salvo su utilidad moderada para cultivos arbóreos o pastos. Debido a su susceptibilidad significativa a la erosión, es conveniente que se mantengan con vegetación. En este orden de ideas, aunque la vegetación original de este segmento del territorio estatal se ha perdido por el crecimiento de la ciudad, la cabecera municipal todavía está circunscrita por bosque de coníferas y encinos, así como por selva baja caducifolia, esta última tiene presencia relevante al norte de la ciudad (Ibid.).

Se requiere formular y poner en práctica acciones relacionadas con la conservación, o recuperación, de las áreas dotadas de esos ecosistemas; ya que la proliferación de asentamientos humanos irregulares, acaecida durante los decenios recientes como resultado de la migración de población procedente de las distintas regiones guerrerenses, ha acelerado la pérdida de los recursos naturales y servicios ambientales que le proporcionan a la ciudad.

Chilpancingo es atravesado por la carretera México-Acapulco, tal particularidad lo ha fortalecido como el sitio que proporciona suministros y servicios tanto a quienes se desplazan por la vía de comunicación señalada o bien desde la Costa Chica hacia el centro del país, así como a los habitantes de los municipios vecinos; en especial Tixtla, Eduardo Neri, Chilapa, Quechultenango y Mochitlán (Villerías, 2008; García, op. cit.).

En esta localidad de la región Centro, la población ocupada se estima en 77191 personas (81.7\% del total municipal). La tasa de desocupación es $3.27 \%$, un valor muy cercano al correspondiente al estado (3.28\%) (INEGI, op. cit.). Según el gobierno de Guerrero, en ese asentamiento, una parte considerable de la población se ocupa en labores relacionadas con las oficinas de gobierno. Asimismo, como en la mayoría de los sitios urbanos de México, destaca la PEA ocupada en el comercio y la oferta de servicios (tiendas de abarrotes, refaccionarías, ferreterías, mueblerías, cerrajerías, 
Neftali Garcia Castro, Salvador Villerias Salinas. The levels of social vulnerability

of the City of Chilpancingo, Guerrero, Mexico

DOI: http://dx.doi.org/10.15359/rgac.1-56.11

vulcanizadoras, gasolineras, talleres mecánicos, farmacias, centros comerciales, restaurantes). Estas actividades se desarrollan, sobre todo, en la parte central de la ciudad.

En buena medida, el reciente cambio rural-urbano de la capital guerrerense se debe a la incorporación constante de población migrante a las actividades para las cuales no se requiere una calificación determinada; aquellos servicios a los que puede integrarse la fuerza de trabajo con escasa o nula formación escolar (servicios domésticos, el pequeño comercio, el ambulantaje, reparación de viviendas) (CollHurtado, 2005). Al igual que en otras ciudades de países periféricos, la terciarización ha sido causa y efecto del crecimiento demográfico, lo que ha incentivado el incremento de los barrios marginales en los que residen personas cuyas vidas se caracterizan por la pobreza y pocas oportunidades para modificar tal condición.

De acuerdo con el CONAPO, a principios de este decenio, solo 3\% de la población de la ciudad de Chilpancingo presentó un grado de marginación muy bajo, esto es 5955 personas concentradas en 4 AGEB de este asentamiento urbano. En contraste, prácticamente $60 \%$ de los habitantes registró grado alto y muy alto, en 88 AGEBS (CONAPO, op. cit.). Estas se localizan tanto en el extremo oriental como en el occidental de la capital guerrerense, por otro lado, las áreas ubicadas en el centro de la cabecera municipal ostentan grado medio y bajo.

\section{Niveles de vulnerabilidad social}

En la capital del estado de Guerrero existen doce niveles de vulnerabilidad social, la preponderancia de indicadores con poca trascendencia cuantitativa es recurrente solo en veinticinco AGEB, esto es $27.2 \%$ del total de áreas analizadas. Las otras sesenta y siete demarcaciones presentan un panorama socioeconómico distinto; la mayoría registra, en por lo menos dos de cinco indicadores ponderados, valores altos y muy altos. Por ejemplo, el índice de marginación alcanza tales rangos en cincuenta y siete AGEB; la relación de dependencia, en treinta y cuatro; el porcentaje de hogares con jefatura femenina, en veinticuatro; y la tasa de desocupación, en dieciocho. En los párrafos subsecuentes se profundiza en el comportamiento de los indicadores socioeconómicos que definen los distintos niveles revelados (Figura 3). 
Nivel I. En esa condición se encuentran siete AGEB ubicadas, sobre todo, en la parte centro-sur de la ciudad de Chilpancingo, próximas al boulevard Vicente Guerrero (el principal eje de comunicación de la capital guerrerense). En esas áreas es importante la proporción de hogares encabezados por mujeres; por lo general, esta registra valores medios. En el resto de los indicadores predominan los rangos bajos y muy bajos. En este sentido, un rasgo sobresaliente es el número de AGEB con índices de marginación bajos, $85.7 \%$ del conjunto examinado en este nivel. Desafortunadamente, esta vulnerabilidad social mínima caracteriza únicamente a $4.7 \%$ de los habitantes de la ciudad.

Nivel II. Corresponde a diez AGEB cuya distribución espacial es similar a la descrita en el párrafo precedente. Sin embargo, este segundo nivel tiene mayor presencia en la sección septentrional de esta localidad guerrerense. Otra diferencia es la significativa concentración territorial de población; $60 \%$ de las áreas ostentan valores altos y muy altos. Esto se debe a que en esta decena de AGEB viven 22047 personas; prácticamente, $25 \%$ de la población total de la ciudad. En términos generales, se trata de espacios cuyo número de habitantes fluctúa entre 1500 y 3500 . En comparación con el nivel I, las tasas de desocupación son mayores; pese a ello, $70 \%$ de los casos están comprendidos en el rango bajo y el resto posee cifras medias. Los demás indicadores exponen un escenario análogo al descrito en el nivel anterior. 
Neftali Garcia Castro, Salvador Villerias Salinas. The levels of social vulnerability of the City of Chilpancingo, Guerrero, Mexico

DOI: http://dx.doi.org/10.15359/rgac.1-56.11

Figura 3. Ciudad de Chilpancingo: niveles de vulnerabilidad social

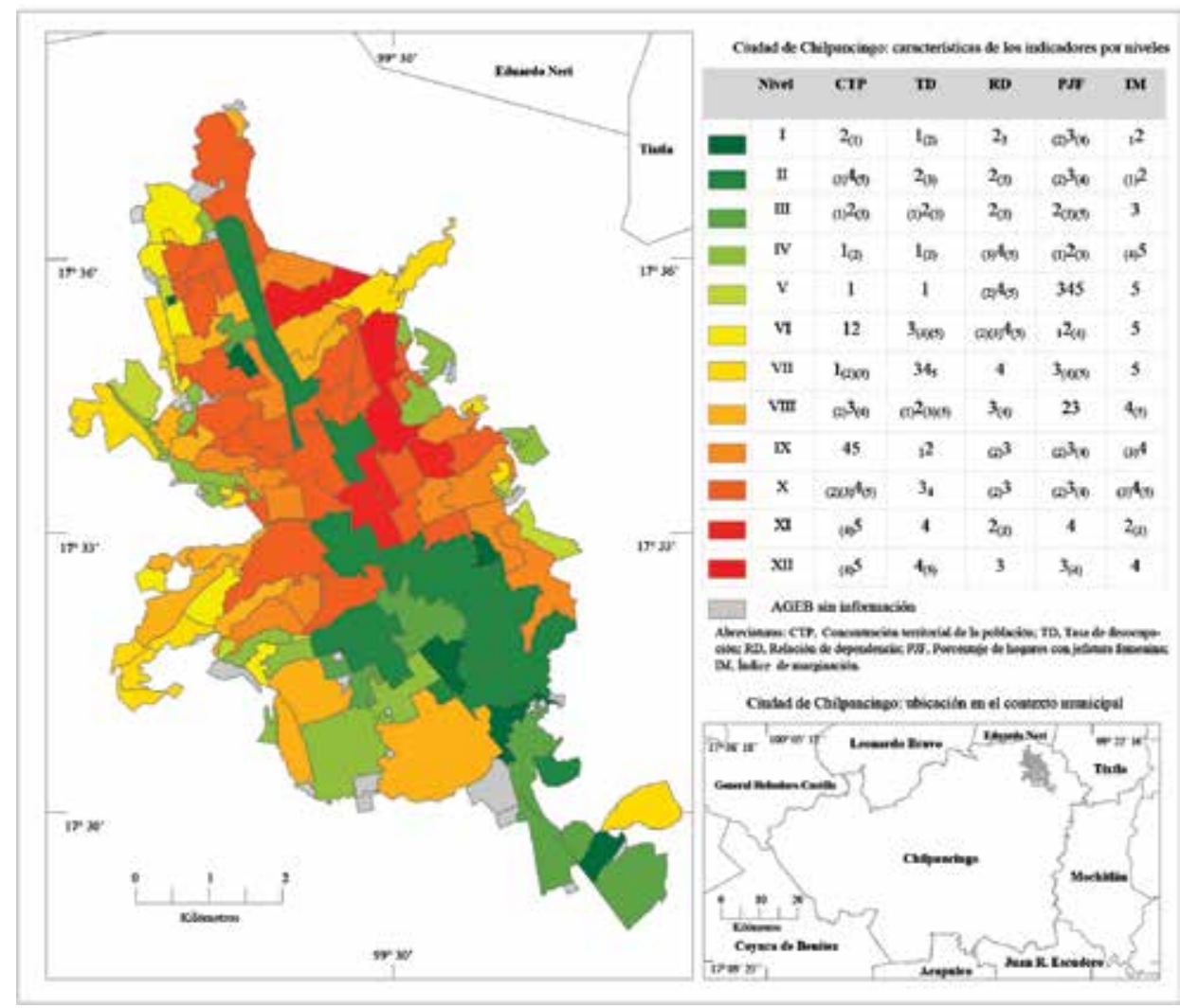

Fuente: elaborado con base en datos de INEGI, op. cit. y CONAPO, op. cit.

Nivel III. Caracteriza a ocho AGEB con índices de marginación ligeramente superiores a los identificados en los dos primeros niveles, aquí hay valores medios. En los otros cuatro indicadores destacan las cifras pertenecientes al rango bajo. Este grupo de AGEB todavía advierte vulnerabilidad social moderada, en tal condición se encuentran 6337 habitantes de la ciudad (7.15\% del total), $72 \%$ de ese monto de población vive en el segmento centro-sur del asentamiento urbano y $28 \%$ en una AGEB localizada al norte, esta alberga 1809 personas, es la más habitada del nivel III.

Nivel IV. Se detecta en diecisiete AGEB ubicadas en la periferia de la ciudad (en la zona noreste, noroeste y suroeste). Esas áreas sobresalen por sus índices de marginación; $76.5 \%$ de las circunscripciones ponderadas 
tienen valores muy altos y el porcentaje restante muestra montos altos. El $64.7 \%$ de los espacios también posee alta relación de dependencia. En contraste, la mayor parte de los códigos denota muy baja concentración territorial de población, esto ocurre en $70.6 \%$ de las AGEB. Un comportamiento similar se descubre al analizar la tasa de desocupación; la cual es muy baja en $76.5 \%$ de los casos evaluados y la proporción de familias encabezadas por mujeres adquiere una expresión cuantitativa mínima, $58.8 \%$ de las jurisdicciones están en el rango bajo.

Nivel $V$. Se presenta en seis AGEB dispersas en el extremo oriental y occidental del asentamiento urbano, allí se aglutinan 991 personas $(1.1 \%$ del total de la ciudad). En esos espacios, la cantidad de habitantes oscila entre 100 y 300 personas, este número mínimo de residentes explica porque la concentración territorial de población es muy baja. También la tasa de desocupación reporta cifras dentro de dicho rango. No obstante, todas las áreas con este nivel de vulnerabilidad social se asocian con índices de marginación muy altos, y tanto la relación de dependencia como el porcentaje de hogares con jefatura femenina exhiben valores sobresalientes, ya que en más del $60 \%$ de las unidades territoriales escrutadas se rebasa el rango medio.

Nivel VI. En este se hallan ocho AGEB con 4123 personas, esto es $4.6 \%$ de los habitantes de la capital guerrerense. A diferencia del número $\mathrm{V}$, aquí se detectan las características siguientes: en la parte noroccidental hay un mayor número de circunscripciones con el sexto nivel de vulnerabilidad social. La concentración territorial de población oscila entre el rango bajo y muy bajo. Más del $50 \%$ de las circunscripciones poseen un índice de marginación muy alto y relación de dependencia alta. La tasa de desocupación es notable; $62.5 \%$ de las AGEB tiene valores medios. Además, hay menor proporción de hogares encabezados por mujeres, $87.5 \%$ de las jurisdicciones analizadas están en el rango bajo.

Nivel VII. Se distingue por los índices de marginación muy altos y relación de dependencia alta, ambas características se manifiestan en catorce AGEB; gran parte de ellas están en la periferia de la ciudad, en la sección noreste y occidente. En este nivel también existen tasas de desocupación importantes; en $57.2 \%$ de los casos, este indicador ostenta valores por encima del rango medio. La mitad de las AGEB evaluadas posee porcentajes medios de hogares con jefatura femenina. El 78.6\% de las áreas 
Neftali Garcia Castro, Salvador Villerias Salinas. The levels of social vulnerability

of the City of Chilpancingo, Guerrero, Mexico

DOI: http://dx.doi.org/10.15359/rgac.1-56.11

exhibe muy baja concentración territorial de población, puesto que en este nivel de vulnerabilidad se encuentran sólo 5719 personas $(3 \%$ del total asentado en la ciudad).

Nivel VIII. Corresponde a un total de catorce AGEB del occidente y norte de la ciudad. La tasa de desocupación y el porcentaje familias con jefatura femenina son los indicadores con menor relevancia cuantitativa; en ambos casos son frecuentes los valores bajos. El 71.4\% de las áreas reporta una condición media en la concentración territorial de población; en la mayoría de las demarcaciones estudiadas, el número de habitantes oscila entre 1000 y 3000 personas. En contraste, los índices de marginación superan el rango medio y la relación de dependencia muestra tanto cifras medias como altas.

Nivel IX. Está presente en once AGEB diseminas en la parte central y occidental del asentamiento urbano. Dicho conjunto de unidades territoriales alberga $17.6 \%$ de la población de la ciudad de Chilpancingo. El número de habitantes de cada área con este nivel de vulnerabilidad social varía entre 1500 y 3000 personas; en consecuencia, la concentración territorial de población es uno de los indicadores sobresalientes, $80 \%$ de los códigos encontrados denota cifras altas. Además, 70\% de los casos evaluados advierte la existencia de índices altos de marginación. En tanto, la relación de dependencia y el porcentaje de hogares encabezados por mujeres muestra predominio de valores medios. La tasa de desocupación tiene un comportamiento diferente, dado que sus cifras quedan comprendidas en los rangos bajo y muy bajo.

Nivel $X$. Las veintitrés AGEB con esta condición se disponen en el área septentrional de la capital de Guerrero. Se trata de espacios densamente poblados, $75 \%$ de ellos tiene entre 2000 y 4000 habitantes, ya que en esa parte de Chilpancingo viven 58074 personas (31.01\% del total de la ciudad). En términos generales, los cinco indicadores evaluados manifiestan valores sobresalientes; en ese sentido, solo uno exhibe un escenario distinto al descrito en el párrafo anterior. El décimo nivel de vulnerabilidad social se distingue por ostentar tasas de desocupación significativas, $87.5 \%$ de las AGEB poseen valores medios y en los espacios restantes se supera tal rango.

Nivel XI. Se identifica en tres AGEB situadas en la parte centroeste de la ciudad de Chilpancingo. Sólo 5.6\% de los habitantes de este 
asentamiento guerrerense reporta dicho nivel de vulnerabilidad social. Tiene elevada concentración territorial de población, pues las cifras relacionadas con este indicador superan el rango medio. Asimismo, las tasas de desocupación y el porcentaje de hogares con jefatura femenina obtienen montos altos. En tanto, la relación de dependencia y el índice de marginación se adjudican, de manera predominante, valores bajos.

Nivel XII. Únicamente tres AGEB muestran este nivel de vulnerabilidad social, la cual se asociada con la parte nororiental de la localidad urbana. Allí se asientan 11958 personas, 6.4\% de los habitantes de la ciudad. Muestra un escenario similar al referido en el párrafo anterior; sin embargo, aquí, además de la concentración territorial de población y la tasa de desocupación, el indicador con expresión cuantitativa relevante es el índice de marginación; en todas las AGEB, este presenta valores altos. Por su parte, la relación de dependencia es media y el porcentaje de hogares con jefatura femenina oscilan entre esta categoría y el rango alto.

\section{Discusión de resultados}

Los niveles de vulnerabilidad social de la ciudad de Chilpancingo son la expresión sintética de un conjunto de características que denotan las condiciones de vida de los habitantes de esta localidad guerrerense; y que, por lo tanto, suelen definir su capacidad para hacer frente a situaciones de emergencia de distinta índole y magnitud, derivadas de aquellos fenómeno naturales o antrópicos que pone en riesgo su integridad física y el desarrollo de sus actividades cotidianas. La tipificación probabilística sirve para "evaluar, desde la perspectiva cuantitativa y cualitativa, la combinación de los atributos territoriales expresados a través de los datos" (Vázquez, 2007, p.100). Brinda elementos esenciales para agrupar "datos que evidencian unidades territoriales básicas con un comportamiento similar" (Ibid.).

En la capital del estado de Guerrero sólo 36\% de la población ostentan vulnerabilidad social mínima (comparada con aquella que exhibe el resto de los residentes de la ciudad). En términos generales, tal condición se detecta en las AGEB que integran la parte centro-sur de Chilpancingo; se trata de la porción territorial asociada con el asentamiento original, buena parte localizado en el valle del río Huacapa. Es un área de suma importancia para la dinámica socioeconómica local y regional debido a que aloja al núcleo histórico, oficinas de gobierno estatales, municipales y 
Neftali Garcia Castro, Salvador Villerias Salinas. The levels of social vulnerability

of the City of Chilpancingo, Guerrero, Mexico

DOI: http://dx.doi.org/10.15359/rgac.1-56.11

aquellas vinculadas con prestadores de servicios profesionales, así como una cantidad significativa de establecimientos comerciales diversos. A pesar de esto, el uso de suelo habitacional es preponderante. De acuerdo con el sustento cognoscitivo y el tratamiento metodológico de los indicadores ponderados, la mayoría de los residentes de esta zona tiene condiciones socioeconómicas que dan pauta para anticipar, lidiar, resistir o recuperarse de situaciones críticas, pues que allí se concentra el sector de la población que ostenta mayor acceso a activos y estructura de oportunidades.

En contraste, una cantidad notable de AGEB con elevados niveles de vulnerabilidad social se localiza tanto en la sección septentrional como en la periferia de la ciudad. Esta última es resultado de la acelerada expansión urbana acaecida en decenios recientes; desafortunadamente, tal proceso ha tenido lugar sobre las laderas de las montañas que circundan a Chilpancingo; en consecuencia, los terrenos presentan pendientes pronunciadas e inestabilidad geológica considerable. En esos espacios ha proliferado el establecimiento de población con escasos recursos económicos, debido a los costos elevados de la vivienda y la falta de predios en otras partes céntricas de la ciudad. Las familias suelen obtener, en ocasiones mediante invasión, terrenos no aptos para el desarrollo habitacional, y, con frecuencia, tienen acceso limitado a servicios públicos (energía eléctrica, agua potable, drenaje).

Sin embargo, el análisis de la tipología revelada permite vislumbrar que los niveles de vulnerabilidad social de cada AGEB no incrementan en función de la distancia que las separa del centro de la ciudad. A menudo, las áreas con niveles disímiles son contiguas, tanto en la parte central como en la periferia del asentamiento urbano. El tratamiento metodológico de los indicadores seleccionados denota algunos rasgos fundamentales de interacción, organización y estratificación social que intervienen en el nivel de acceso a activos y estructura de oportunidades. Además, da cuenta de la heterogénea distribución espacial de tal conjunto de características.

Por lo tanto, el empleo de esta propuesta metodológica brinda elementos para “... establecer proyecciones territoriales a partir de los patrones que se detectan y, sobre todo, incidir mediante el conocimiento más profundo de los procesos socioeconómicos en una mejor organización para el aprovechamiento del espacio..." (García, 1993, p.73). Resultan prioritarias las AGEB con niveles VIII, IX y X, estos muestran vulnerabilidad social marcada como resultado del índice de marginación alto y valores 
notables asociados con la tasa de desocupación, relación de dependencia o el porcentaje de hogares encabezados por mujeres, así como elevada concentración de población; en conjunto, esas áreas albergan 60251 habitantes (32.1\% del total de la ciudad). Esto representa un número importante de personas sin la capacidad suficiente para compensar los efectos negativos que pueden generar algunos fenómenos, naturales o antrópicos, sobre su bienestar.

De esta manera, además de los criterios explicados en el apartado metodológico de esta investigación, la concentración territorial de población es fundamental para identificar los espacios que advierten menor o mayor vulnerabilidad social en este asentamiento guerrerense. Los niveles XI y XII aglutinan las áreas más pobladas de la localidad; prueba de ello es que en las seis AGEB con tales niveles vive más de $10 \%$ de los habitantes de Chilpancingo; del mismo modo, por lo menos tres indicadores evaluados registran valores sobresalientes, la mayoría por arriba del rango medio. Asimismo, los niveles IV, V, VI y VII destacan por ostentar montos muy altos, relacionados con el índice de marginación y la relación de dependencia, una condición que corresponde a $21.3 \%$ de los residentes de la ciudad. Con base en lo descrito, únicamente $36.6 \%$ de la población tendría capacidad substancial de resiliencia tanto en las fases de emergencia como en la recuperación derivadas de un evento adverso, esto es sólo las personas que viven en las áreas con niveles I, II y III.

\section{Conclusión}

En decenios recientes, ha surgido una cantidad importante de investigaciones sobre la vulnerabilidad desde la perspectiva social; una buena parte de esos trabajos examina las condiciones de vida de personas, hogares o grupos socioeconómicamente desfavorecidos, con la finalidad de revelar elementos epistemológicos que favorezcan el diseño de estrategias en la materia (Sánchez y Egea, op. cit.). El análisis de la ciudad de Chilpancingo, desde la óptica descrita en las páginas precedentes, contribuye substancialmente a la elucidación de aspectos socioeconómicos que deben considerarse fundamentales para el diseño de políticas públicas, así como en la gestión del territorio. La proliferación de ese tipo de trabajos favorece la consolidación de un marco cognoscitivo que ofrezca elementos para explicar objetivamente porque el panorama de la capital guerrerense 
Neftali Garcia Castro, Salvador Villerias Salinas. The levels of social vulnerability

of the City of Chilpancingo, Guerrero, Mexico

DOI: http://dx.doi.org/10.15359/rgac.1-56.11

resulta complejo, pues se requieren reflexiones consistentes en torno a los modelos de desarrollo económico impuestos y sus repercusiones sobre el bienestar de la población, la necesidad imperante de construir alternativas político-económicas congruentes con los retos sociales actuales y sobre los mecanismos de regulación de los asentamientos humanos de la ciudad.

Existen diversas alternativas técnicas para evaluar la vulnerabilidad social que ostenta un espacio, algunas de ellas están descritas en el sustento cognoscitivo de esta investigación. Los interesados en este tema suelen optar por metodologías que han mostrado su utilidad para evidenciar "la incapacidad de una persona o de un hogar para aprovechar las oportunidades, disponibles en distintos ámbitos socioeconómicos, para mejorar su situación de bienestar o impedir su deterioro" (Kaztman, op. cit., p.13). No obstante, también se puede recurrir a propuestas metodológicas que emergieron con una finalidad investigativa distinta, tal es el caso de la tipificación probabilística que, con pocos indicadores, da pauta para revelar el comportamiento esencial del fenómeno de interés, lo cual supone poner mayor atención sobre la cualidad-complejidad de los atributos elegidos, por encima de la cantidad de indicadores seleccionados (Propin, op. cit.). En ambos casos, es fundamental cotejar el diseño de la secuencia a seguir con los lineamientos teórico-conceptuales de la vulnerabilidad social, los objetivos del trabajo y las fuentes de información disponibles.

\section{Referencias}

Adamo, S. B. (2012). Vulnerabilidad social. Recuperado de: http://moodle.mininterior.gov.ar/biblioteca_dnpc/talleres/adamo_VulnerabilidadSocial julio31.pdf

Águila, E., Mejía, N., Pérez, F. y Rivera, A. (2013). Pobreza y vulnerabilidad en México: El caso de los jóvenes que no estudian ni trabajan. Santa Mónica, California: Rand Corporation.

Alfageme, M. A. y Carrasco, A. (2010). Midiendo la vulnerabilidad de los hogares en el Perú. Recuperado de: http://www.bcrp.gob.pe/docs/ Proyeccion-Institucional/Encuentro-de-Economistas/EE-2010-XXVIII/EE-2010-D3-Alfageme-Carrasco.pdf

Aneas, S. (s/f). Vulnerabilidad global: variables y medición. Recuperado de: http://www.ffha.unsj.edu.ar/geories/documentos/vulnerabilidadglobal.pdf 
Arreola, J. (2011). Variación espacio-temporal de la sismicidad en el estado de Guerrero 1998-2010. Tesis de ingeniería. Facultad de Ingeniería, UNAM. México. (p.60).

Beck, U. (2008). La sociedad del riesgo mundial. En busca de la seguridad pérdida. Barcelona, España: Editorial Paidós.

Birkmann, J. y Fernando, N. (2008). Measuring revealed and emergent vulnerabilities of coastal communities to tsunami in Sri Lanka. En: Disasters, 32(1), 82-105.

Bitrán, D. (2001). Características del impacto socioeconómico de los principales desastres ocurridos en México en el período 1980-99. Distrito Federal, México: SEGOB.

Busso, G. (2005). Pobreza, exclusión y vulnerabilidad social. Usos, limitaciones y potencialidades para el diseño de políticas de desarrollo y de población. En: Tandil, VIII Jornadas Argentinas de Estudios de Población, Asociación de Estudios de la Población. (pp. 1-27).

Busso, G. (2002). Vulnerabilidad sociodemográfica en Nicaragua: un desafio para el crecimiento económico y la reducción de la pobreza. Santiago de Chile, Chile: Publicación de las Naciones Unidas.

Caro, E. (2003). La vulnerabilidad social como enfoque de análisis de la política de asistencia social para la población adulta mayor en México. Recuperado de: http://www.cepal.org/celade/noticias/paginas/9/12939/eps9_ecaro.pdf

Cabrales, L. F. (2006). “Geografía y Ordenamiento Territorial”. Tratado de Geografia Humana. Barcelona, España: Anthropos / Universidad Autónoma Metropolitana. (pp. 601-627).

Cecchini, S., Espíndola, E., Filgueira, F., Hernández, D. y Martínez, R. (2012). Vulnerabilidad de la estructura social en América Latina: medición y políticas públicas. En: Realidad, datos y espacio, revista internacional de estadistica y geografía, 3(2), 32-45.

CELADE (2002). Vulnerabilidad Sociodemográfica: viejos y nuevos riesgos para comunidades, hogares y personas. Brasilia, Brasil: Publicación de las Naciones Unidas.

CEPAL-ECLAC (2002). Vulnerabilidad Sociodemográfica: viejos y nuevos riesgos para comunidades, hogares y personas. Brasilia, Brasil: Publicación de las Naciones Unidas. 
Neftali Garcia Castro, Salvador Villerias Salinas. The levels of social vulnerability

of the City of Chilpancingo, Guerrero, Mexico

DOI: http://dx.doi.org/10.15359/rgac.1-56.11

CEPEP. (1997). Evaluación social del proyecto de saneamiento y encauzamiento del río Huacapa en la ciudad de Chilpancingo, Guerrero. Recuperado de: http://www.cepal.org/ilpes/noticias/paginas/1/52961/ Doc-47.pdf

Coll-Hurtado, A. (2005). México: una visión geográfica. Distrito Federal, México: Universidad Nacional Autónoma de México.

CONAPO. (2010). Índice de marginación urbana 2010. Distrito Federal, México: Consejo Nacional de Población.

CONEVAL. (2015). Rezago social a nivel zonas urbanas (AGEB urbanas). Recuperado de: http://www.coneval.gob.mx/Medicion/Paginas/Rezago_social_AGEB_2010.aspx

Coy, M. (2010). Los estudios del riesgo y de la vulnerabilidad desde la geografía humana. Su relevancia para América latina. En: Población y Sociedad, 17, 9-28.

Cutter, S. L., Boruff, B. J. y Shirley, W. L. (2003). Social Vulnerability to Environmental Hazardsn. En: Social Science Quarterly, 84(2), 242-261.

Derrick, W., Kates, R. y Phillips, L. (1968). Human reponse to Weather and climate. Geographical contributions. En: The Geographical Review, 57, 262-280.

Filgueira, C. (2005). Estructura de oportunidades, activos de los hogares y movilización de activos en Montevideo (1991-1998). En: Prisma, 21, 67-115.

García, A. (1993). Asimilación económica del territorio (un nuevo enfoque en la interpretación regional del país). En: Investigaciones Geográficas, Boletín 27, 69-94.

García, N. (2011). Los grados de asimilación económica del estado de Guerrero, a fines del siglo XX. Tesis de doctorado en Geografía. Facultad de Filosofía y Letras, UNAM. México. (pp. 186).

Golovanevsky, L. (2007). Vulnerabilidad y transmisión intergeneracional de la pobreza. Un abordaje cuantitativo para Argentina en el siglo $X X I$. Tesis doctoral. Facultad de Ciencias Económicas, Universidad de Buenos Aires. Argentina. (pp. 450).

INEGI (2015). Sistema Estatal y Municipal de Base de Datos. Recuperado de: http://sc.inegi.org.mx/cobdem/ 
Juárez, M. C.; Iñiguez, L. y Sánchez, M. A. (2006). Niveles de riesgo social frente a desastres naturales en la Riviera Mexicana. Investigaciones Geográficas, Boletín del Instituto de Geografía, 61, 75-88.

Kaztman, R. (2000). Notas sobre la medición de la vulnerabilidad social. En: Documentos de Trabajo del IPES, 2, 275-301.

Lampis, A. (2010). ¿Qué ha pasado con la vulnerabilidad social en Colombia? Conectar libertades instrumentales y fundamentales. En: Revista Sociedad y Economía, 19, 229-261.

López, A. (2009). Análisis cartográfico geomorfológico del centro-oriente del estado de Guerrero. Tesis de licenciatura en Geografía. Facultad de Filosofía y Letras, UNAM. México. (pp. 83).

Moreno, J. C. (2008). El concepto de vulnerabilidad social en el debate en torno a la desigualdad: problemas, alcances y perspectivas. En: $O b-$ servatory on Structures and Institutions of Inequality in Latin America, Working paper series, 9, 2-38.

Pizarro, R. (2001). La vulnerabilidad social y sus desafíos: una mirada desde América Latina. Santiago de Chile, Chile: Publicación de las Naciones Unidas.

Propin, E. (2003). Teorías y métodos en Geografía Económica. Distrito Federal, México: Universidad Nacional Autónoma de México.

Propin, E. (1989). "Sección Regionalización Económica". Nuevo Atlas Nacional de Cuba. Madrid, España: Instituto de Geografía de la Academia de Ciencias de Cuba e Instituto Geográfico Militar de España. Propin, E. y Sánchez, Á. (1998). Niveles de asimilación económica del estado de Guerrero. En: Investigaciones Geográficas, 37, 59-70.

Quinn, L. (2013). Determinantes de la pobreza y vulnerabilidad social en República Dominicana, 2000-2012. Santo Domingo, República Dominicana: Banco Central de la República Dominicana.

Rodríguez, J. M. (2004). Los desastres de origen natural en México: el papel del FONDEN. En: Estudios Sociales, XII,(23), 74-96.

Ruiz, M. (2012). Vulnerabilidad territorial frente a desastres naturales: el caso de la isla de Mallorca (Baleares, España). GeoFocus, 12, 16-52.

Ruiz, M. y Grimalt, M. (2012). Análisis de la vulnerabilidad social frente a desastres naturales: el caso de la isla de Mallorca. En: Geografia y Sistemas de Información Geográfica (GEOSIG, 4(4), 1-26. 
Neftali Garcia Castro, Salvador Villerias Salinas. The levels of social vulnerability

of the City of Chilpancingo, Guerrero, Mexico

DOI: http://dx.doi.org/10.15359/rgac.1-56.11

Ruíz, N. (2011). La definición y medición de la vulnerabilidad social. Un enfoque normativo. En: Investigaciones Geográficas, 77, 63-74.

Salamanca, L. A. (2009). "Estudio de resiliencia en desastres naturales en seis barrios de la ciudad de La Paz, Bolivia". Vulnerability from resiliencia. La Paz, Bolivia: UNICEF. (pp. 206-222).

Sales, F. J. (coord.) (2012). Pobreza y factores de vulnerabilidad social en México. Distrito Federal, México: Centro de Estudios Sociales y de Opinión Pública.

Sánchez, A. (2000). Marginación e ingreso en los municipios de México (análisis para la asignación de recursos fiscales). Distrito Federal, México: Miguel Ángel Porrúa-Instituto de Investigaciones Económicas, UNAM.

Sánchez, D. y Egea, C. (2011). Enfoque de vulnerabilidad social para investigar las desventajas socioambientales. Su aplicación en el estudio de los adultos mayores. En: Papeles de Población,17(69), 151-185.

Secretaría de Ambiente y Desarrollo Sustentable (2015). Indicadores de desarrollo sostenible. Recuperado de: http://www.ambiente.gov. ar/?idarticulo $=6314$

Secretaría de Gobernación (2015). Boletines de Prensa Septiembre 2013. Recuperado de: http://www.gobernacion.gob.mx/es/SEGOB/Sintesis_Informativa?cat $=\mathrm{http} \% 3 \mathrm{~A} \% 2 \mathrm{~F} \% 2 \mathrm{Fwww} . \mathrm{SEGOB}$. swb\%23swbpress_Category\%3A1

Vázquez, V. (2007). Valoración de las condiciones naturales asociadas con el desarrollo de la actividad turística en el estado de San Luis Potosí, México. En: Espacio y Desarrollo, 19, 93-103.

Vergara, R. (2011). Vulnerabilidad social y su distribución espacial: el caso de las entidades federativas de México, 1990-2010. En: Paradigma económico, 3(2), 85-111.

Villafuerte, C. D. (2014). Modelado poroelástico de sismos silenciosos en Guerrero, México. Tesis de ingeniería geofísica. Facultad de Ingeniería, UNAM. México. (pp. 124).

Villerías, S. (2008). "La ciudad de Chilpancingo: nodo principal de la dinámica de servicios de la región Centro del estado de Guerrero". Geografía y procesos territoriales en el estado de Guerrero. Distrito Federal, México: Universidad Autónoma de Guerrero-Sociedad Mexicana de Geografía y Estadística. (pp. 197-216). 